\title{
Verbal facilitation of face recognition
}

\author{
CHARITY BROWN and TOBY J. LLOYD-JONES \\ University of Kent, Canterbury, England
}

\begin{abstract}
We examined the effects of verbally describing a face on face memory, as assessed in an old/new recognition task. Experiment 1 established that describing faces facilitated their later recognition. In Experiment 2, we argue that verbalization facilitated the recognition of faces that had been previously described, but not of faces intermingled with the described faces. In Experiment 3, the participants described (or did not, in the control condition) either differences or similarities between pairs of faces. Verbal facilitation was equivalent for both types of descriptions. Finally, in Experiment 4, the participants were instructed to generate either holistic or featural descriptors. Verbal facilitation was equivalent for both types of descriptors. We discuss these findings in terms of the nature of the verbalization that benefits face recognition.
\end{abstract}

Do we think before we speak, or does language shape our thoughts? Research from a number of different areas in psychology suggests that although language may structure cognition, cognition may also exceed language (for reviews, see Glucksberg, 1988; Harley, 1995). For instance, experiences that are inherently difficult to put into words, such as seeing beauty in a work of art, suggest that some cognitions cannot be fully captured by language. We focus here on the more tractable problem of how verbally describing a cognition that is normally difficult to describe (such as one's memory of a face) may influence behavior. As we shall see, such verbal re-representation can have both beneficial and detrimental influences on subsequent performance. Examining these phenomena should help us toward a fuller understanding of the complex relationship between language and cognition.

Our capacity for face recognition exceeds our ability to articulate the basis of our recognition decisions. For instance, verbal descriptions of faces are often too vague to allow judges to distinguish the described face from similar distractors (e.g., Ellis, Shepherd, \& Davies, 1980). Nevertheless, despite the disparity between nonverbal and verbal memory for faces, a number of studies have demonstrated that describing a face can either facilitate or interfere with subsequent visual recognition. Verbal facilitation has been reproduced in a number of studies (e.g., Bloom \& Mudd, 1991; Bower \& Karlin, 1974; Mueller, Courtois, \& Bailis, 1981). Verbal interference has also been observed, albeit less frequently (for a review, see Schooler, 2002). Nevertheless, accounts of these phenomena remain controversial, with no clear consensus. The focus of the present

This research was supported by ESRC Postdoctoral Fellowship T02627-1240 to C.B. and ESRC Research Grant RES000-23-0057 to T.J.L.-J. Correspondence concerning this article should be addressed to C. Brown, Institute of Psychological Sciences, University of Leeds, Leeds LS2 9JT, England (e-mail: psccbr@leeds.ac.uk). article is on establishing a new paradigm with which to examine verbal facilitation of face recognition.

Most research on verbal facilitation has focused on the levels-of-processing effect demonstrated by Bower and Karlin (1974, Experiments 1 and 2). They found that personality trait judgments (e.g., niceness) to unfamiliar faces improved subsequent recognition performance more than did judgments about physical characteristics, such as gender. Three broad accounts of the levels-of-processing effect can be distinguished, on the basis that facilitation is due to (1) a greater number of features attended to and stored during encoding (the feature quantity account; see, e.g., Winograd, 1978, 1981), (2) the encoding of more global impressions of the face, in addition to featurebased information (the holistic account; see, e.g., Wells \& Hryciw, 1984), and (3) the formation of richer semantic associations with the target face that benefit retrieval (the semantic processing account; see, e.g., J. R. Anderson \& Reder, 1979; Bruce \& Young, 1986; Ryan \& Schooler, 1994, cited in Schooler, Ryan, \& Reder, 1996). These accounts are not mutually exclusive, since, for instance, semantic processing may influence visual-encoding strategies (e.g., Kerr \& Winograd, 1982; Klatzky, Martin, \& Kane, 1982).

Overall, the evidence supports the notion that semantic association of the visual stimulus with a verbal context or a category prototype (e.g., a hobby or an occupation) can enhance recognition performance (e.g., Kerr \& Winograd, 1982; Klatzky et al., 1982; McKelvie, 1985). The evidence concerning feature quantity, however, is more controversial. Whereas a number of studies have suggested that the levels-of-processing effect is not attributable to the number of features that are encoded (e.g., McKelvie, 1985; Patterson \& Baddeley, 1977; Wells \& Hryciw, 1984), other studies have lent some support to the account (e.g., Blaney \& Winograd, 1978; Bloom \& Mudd, 1991; Courtois \& Mueller, 1979; Winograd, 1976, 1978, 1981). Finally, the evidence for the holistic account, which proposes that global impressions are formed through the en- 
coding of relationships between some or all features (i.e., conjoint and spatial-relational information; see Peterson \& Rhodes, 2003, for a recent discussion of distinctions concerning more global and local aspects of face processing), is also mixed (e.g., Berman \& Cutler, 1998; Mueller \& Wherry, 1980; Wells \& Hryciw, 1984). For instance, stimulus inversion, which is proposed to selectively interfere with the perception of holistic information, has been shown to interact with levels of processing. However, the effect is not robust (e.g., McKelvie, 1991, 1995, 1996).

The picture is complicated by the fact that verbally describing a stimulus can also interfere with subsequent recognition. For instance, in a seminal study, Schooler and Engstler-Schooler (1990) presented a video of a bank robbery, after which participants had to describe (or not, in the control condition) the facial features of the bank robber. Description condition participants were less able to subsequently identify the robber. They termed this interference verbal overshadowing. Verbal overshadowing is not restricted to the stimulus that is described. For instance, Brown and Lloyd-Jones $(2002,2003)$ have demonstrated that describing a single face can subsequently impair recognition of a relatively large number of both faces and cars (see also Dodson, Johnson, \& Schooler, 1997; Westerman \& Larsen, 1997). Two accounts of verbal overshadowing are predominant, one of which seems more appropriate to interference on recognition of a particular face that is described, and the other more appropriate to a more general form of interference (Brown \& Lloyd-Jones, 2002). (1) Meissner, Brigham, and Kelley (2001; see also Meissner \& Brigham, 2001) have proposed a misinformation account, whereby nonveridical information elicited by the description impacts unfavorably upon memory for the described face. Thus, effects of misinformation depend on altering the memory representation of a particular face in some way that corresponds to verbal activity. (2) Schooler, Fiore, and Brandimonte (1997) have proposed a transfer-inappropriate retrieval account. In essence, following encoding, the application of verbal processes and recall of verbalizable aspects of the stored memory interfere, in some general way, with the utilization of nonverbal processes, omitted in the initial verbal retrieval, that are useful for recognition. There is a shift in processing style, rather than an alteration to a particular memory representation.

\section{A New Paradigm}

We present a novel paradigm, in which our aim is to establish verbal facilitation across recognition of a relatively large number of faces. The general paradigm is as follows. In a study phase, participants viewed and then described (or did not) their visual memory of a series of faces. Subsequently, they had to discriminate the original faces from distractors in a recognition task. Two previous studies, which have demonstrated both beneficial and detrimental effects of verbalization across multiple faces, are of particular relevance here.

Exposure to multiple faces can lead to both proactive (i.e., encoding of faces later on is impaired by prior expo- sure to earlier faces) and retroactive (i.e., when recognition is tested later on, the retrieval of faces is impaired by prior exposure to earlier recognition tests) interference (e.g., Davies, Shepherd, \& Ellis, 1979; Deffenbacher, Carr, \& Leu, 1981). However, Ryan and Schooler (1994, cited in Schooler et al., 1996) found that this interference was reduced by verbalization. In their study, participants sequentially viewed and described each of four faces and then were given four recognition tests, one for each face, presented in an order corresponding to that in which the faces had been encountered. For control (i.e., no-description) participants, performance declined substantially over the four recognition tests, presumably with the buildup of interference. However, for description participants, interference was much less apparent. This suggests that verbalizing individual faces may protect them from the proactive and retroactive interference likely to arise with exposure to multiple stimuli within a similar encoding context.

Nevertheless, Brown and Lloyd-Jones $(2002,2003)$ have previously reported interfering effects of verbalization on face and car recognition in a paradigm similar to that developed here. In the study phase of their paradigm, participants were exposed to 12 to-be-remembered stimuli and then described (or did not) an additional stimulus (a 13th face or car). Verbal interference arose for both face and car recognition. They argued that verbalization encourages a shift toward greater visual processing of individual facial features, at the expense of holistic processing, which is generally more beneficial for the recognition of highly visually similar objects, such as faces and cars. This suggests that we may observe effects of verbal interference, rather than facilitation, here.

Importantly, however, a key difference between the paradigm of Brown and Lloyd-Jones $(2002,2003)$ and the paradigm presented here is that Brown and Lloyd-Jones asked their participants to describe a single face, which then impaired recognition of a number of different faces. However, in the present paradigm, participants describe each face in a series and are later asked to recognize the same faces that they have previously described. The relationship between the to-be-recognized face and the verbal description is likely to be a crucial factor in determining a facilitative influence of verbalization on subsequent recognition performance (Brown \& Lloyd-Jones, 2002). As was outlined earlier, accounts of verbal facilitation have emphasized the elaboration of memory representations corresponding to particular faces. In contrast, Brown and Lloyd-Jones argued that the effects of verbal interference evident in their paradigm reflected a general shift in processing style, rather than any alteration to a particular memory representation. Thus, we predict that facilitative effects of verbalization will arise in the present paradigm, because participants are required to describe each face that they subsequently attempt to recognize.

Establishing verbal facilitation of face recognition in Experiment 1 will allow us to then determine recognition efficiency as a function of verbalization under both free description conditions and conditions in which the participants are constrained to describe the faces in a par- 
ticular way (e.g., with instructions to describe one face and not another or to describe differences or similarities between pairs of faces). The paradigm will also allow us to examine both the qualitative and the quantitative nature of the face descriptors (e.g., whether descriptors refer to more holistic aspects of the face that was described or to individual features) and how these are associated with recognition performance. Together, these methods should provide insight into the nature of the effects of verbalization on face recognition.

\section{EXPERIMENT 1}

In Experiment 1, our aim was to establish an effect of verbal facilitation of face recognition. In a study phase, the participants viewed and described (or did not, in the control condition) each of 12 to-be-remembered faces. Subsequently, the participants had to discriminate the original 12 (old) faces from 12 (new) distractors in a yes/ no recognition task.

\section{Method}

Participants. Sixty-four undergraduate students (43 of them female, 12 of them males, and 9 unclassified due to a procedural error) from the University of Kent participated in partial fulfillment of a course requirement. All were native English speakers, with normal or corrected-to-normal vision.

Materials and Apparatus. The face stimuli presented at study and test were grayscale head-and-shoulder photographs of 48 Caucasian men. To ensure that the recognition task involved face recognition, rather than image recognition, two views of each face were used (Baddeley \& Woodhead, 1983; Sporer, 1991). For each face, a full frontal view was presented during the study phase, whereas a $3 / 4$ view (facing left) was presented at test.

All the photographs were taken from the University of Stirling Psychology Department Psychological Image Collection (i.e., the PICS database at pics.psych.stir.ac.uk). None of the faces had any distinctive marks or wore glasses or a beard. The photographs were edited to remove clothing cues. The 48 faces were divided on the basis of dark and light hair color into two stimulus blocks, each containing 24 stimuli. Within each of the two stimulus blocks, the faces were further randomly divided into two sets of 12 faces, providing four sets of 12 faces in total.

The stimuli were presented on a Power Macintosh 7200/900 computer using SuperLab, Version 1.4 (Cedrus Corporation). The face stimuli appeared in the center of the computer screen, and each stimulus was created within a surface area of $10 \times 9.5 \mathrm{~cm}$.

Design and Procedure. A single-factor design was employed, with description (description vs. no description) as a within-participants factor. The dependent variables were taken from signal detection theory and were discrimination $\left(d^{\prime}\right)$ and response bias $(C)$.

Each participant took part in a description and a no-description condition. Thus, each participant viewed two separate stimulus blocks, one after the other, and each block comprised 12 targets in the study phase and the same 12 targets plus 12 distractors taken from the same block of 24 stimuli in the test phase. In this way, four sets of 12 faces were rotated across the description and nodescription conditions, so that each set appeared equally often as either targets or distractors for an equal number of participants (i.e., for 16 participants within each condition) and no face was encountered more than once for any participant.

In addition, the order in which the participants undertook the description conditions was counterbalanced, with half of the 64 participants undertaking the description condition as the first experimental condition and half the no-description condition as the first experimental condition. Accuracy in the recognition test was measured by a keypress response.

During the study phase, following the presentation of each face, the participants were provided with $15 \mathrm{sec}$ in which to undertake the experimental manipulation. Description participants wrote a verbal description of each face immediately after it had been presented. No-description participants undertook a filler task.

Each participant was tested individually. The following procedure was adopted for both the description and the no-description conditions. In the study phase, the participants viewed 12 sequentially presented faces. Each face remained on the screen for $2 \mathrm{sec}$ and was preceded by a fixation cross presented for $250 \mathrm{msec}$. Following each face, there was a 15 -sec interval, during which the participants wrote a description or completed a filler task (details below). At the end of the $15 \mathrm{sec}$, the computer sounded to alert the participants to return their attention to the screen. A prompt on the screen asked the participants to press the space bar on the keyboard in order to view the next face. Prior to viewing the faces, the participants were instructed to study each face for the whole time that it appeared on the screen. In addition, the participants were informed that they would later be asked to recognize the faces that they were about to see but that, in the recognition test, each of the faces would be presented in a view that was different from how they would appear in the study phase.

Prior to the study phase, the participants were also provided with instructions concerning the experimental manipulation. In the description condition, the participants were told that during the $15-\mathrm{sec}$ interval that followed each face, they would have to write a description of the face that they had just viewed. The precise description instructions were as follows: "Please be as complete in your description as possible, so that another person seeing only your description, could get as accurate an idea as possible of what the face is like." In contrast, in the no-description condition, the participants were told that they would undertake a pen-and-paper filler activity that consisted of a series of visual puzzles (e.g., spot the differences, identify the next pattern in the series, etc.).

Immediately following the study phase, recognition was tested in a yes/no decision task in which the 3/4 views of the 12 study faces were mixed randomly with $3 / 4$ views of 12 new faces. The participants were instructed to respond yes if the face had appeared in the study phase and $n o$ if it had not. The recognition decision was indicated by pressing one of two keys ( $\mathrm{Z}$ or $\mathrm{M})$ on the computer keyboard. Decision key mapping and hand dominance were counterbalanced. Each face remained in view until the participant responded. The participants were instructed to respond as quickly and accurately as possible. Following the completion of the recognition test for the first experimental condition (e.g., the description condition), the participants immediately began the second experimental condition (e.g., the no-description condition). They were informed that the second phase of the experiment contained completely new faces and that the task that intervened between viewings of the faces would be different.

\section{Results}

Analyses of accuracy were carried out to assess whether verbalization influenced discrimination $\left(d^{\prime}\right)$ or response bias $(C)$. For all the experiments, statistical analyses of discrimination and response bias were calculated according to the prescriptions set out by Snodgrass and Corwin (1988). That is, difficulties arise for the signal detection theory model at hit or false alarm rates of 1 or 0 . Therefore, we transformed accuracy data by adding 0.5 to each frequency and dividing by $N+1$, where $N$ was the number of old or new trials/stimuli. For $d^{\prime}$, larger values indicate a greater ability to discriminate between old and new items 
in the recognition test. For $C$, values above 0 indicate a conservative bias (i.e., a tendency to respond no), and values below 0 indicate a liberal bias in the recognition test.

Analyses were carried out by participants and by items. The by-participants analysis involved computing a $d^{\prime}$ and a $C$ score for each participant by pooling data across the different items in a particular condition. The by-items analysis involved computing a $d^{\prime}$ and a $C$ score for each item by pooling data across the different participants responding to that particular stimulus in a particular condition. The subscripts 1 and 2 attached to the $F$ statistic refer to the by-participants and the by-items analyses, respectively.

One-way ANOVAs were carried out on the discrimination and response bias data, with description (description vs. no description) as a within-participants factor. Table 1 shows mean discrimination, response bias, hits, and false alarms as a function of description condition. For all the experiments, main effects or interactions that failed to reach significance are not reported.

Discrimination. There was a significant main effect of description $\left[F_{1}(1,63)=6.13, M S_{\mathrm{e}}=0.30, p<.05\right.$, and $\left.F_{2}(1,47)=11.83, M S_{\mathrm{e}}=0.26, p<.005\right]$. The ability of the participants to discriminate between old and new faces was better in the description than in the no-description condition.

Response bias. There was a significant main effect of description $\left[F_{1}(1,63)=8.23, M S_{\mathrm{e}}=0.05, p<.01\right.$, and $\left.F_{2}(1,47)=4.37, M S_{\mathrm{e}}=0.10, p<.05\right]$. The participants were more liberal in their responding in the description condition than in the no-description condition.

\section{Discussion}

In a novel paradigm, describing the visual memory of each face in a series benefited subsequent discrimination of those faces from new faces in an old/new recognition task.

The effects of verbal facilitation found here contrast with the effects of verbal interference previously demonstrated by Brown and Lloyd-Jones (2002, 2003). In the present paradigm, the participants described each face in the series. In contrast, in the interference paradigm of Brown and Lloyd-Jones, the participants provided a verbal description of an additional stimulus after the presentation of a series of faces. Brown and Lloyd-Jones argued that interference was mediated by a shift in processing strategy

Table 1

Means and Standard Deviations for Discrimination, Response Bias, Hits, and False Alarms for Experiment 1

\begin{tabular}{lccccc}
\hline & \multicolumn{2}{c}{ Bias, Hits, and False Alarms for Experiment $\mathbf{~}$} \\
\cline { 2 - 3 } & $M$ & & & \multicolumn{2}{c}{ No Description } \\
\cline { 2 - 3 } \cline { 5 - 6 }$d^{\prime}$ & 1.18 & 0.53 & & 0.94 & $S D$ \\
$C$ & 0.19 & 0.31 & & 0.30 & 0.61 \\
Hits & 0.65 & 0.15 & & 0.57 & 0.16 \\
False alarms & 0.21 & 0.12 & & 0.23 & 0.13 \\
\hline
\end{tabular}

Note-For the $d^{\prime}$ measure, larger values indicate a greater ability to discriminate between old and new items. For the $C$ measure, values above 0 indicate a conservative response bias, and values below 0 indicate a liberal response bias. from more holistic visual processing, which is useful for discriminating between highly visually similar objects, toward processing of individual facial features. In this way, the participants shifted their processing style from one more useful for visual recognition to one more useful for providing a verbal description.

We suggest that the facilitative effects of verbalization observed here might have been restricted to the recognition of faces that had initially been described and, therefore, might have depended on memory representations corresponding to verbal activity, rather than on a shift in the participants' general processing strategy. Nevertheless, it remains possible that verbalization produces a non-stimulus-specific influence on participants' processing strategies that benefits subsequent recognition performance. In Experiment 2, we examined whether facilitation is restricted to described faces.

\section{EXPERIMENT 2}

In Experiment 2, the participants were presented with a series of faces and, in the description condition, were instructed to describe some faces and not others. Described and nondescribed faces were presented serially and on alternative trials. In the no-description condition, a filler task was completed. If verbal facilitation in the present paradigm arises because the participants in the description condition adopt some general processing strategy that is useful for subsequent recognition, facilitative effects of verbalization may transfer to faces in the series that have not been described. Alternatively, if verbal facilitation is mediated by a memory representation corresponding to verbal activity and specific to the stimulus that is described, the effects of verbalization should be restricted to recognition of those faces in the series that have been described.

We should note that this paradigm also allows for the intriguing, but perhaps unlikely, possibility that facilitation is observed for previously described faces and interference is observed for nondescribed faces (i.e., nondescribed faces encountered in the same series as described faces, where performance on these faces is compared with a control condition that comprises a series of nondescribed faces). For instance, in a study by Dodson et al. (1997), participants described one of two previously seen faces. They observed that verbalization impaired recognition of the nondescribed face (as well as the described face). Here, describing a face may benefit its recognition but also interfere with recognition of a subsequently encountered nondescribed face.

\section{Method}

Participants. Sixty undergraduate students (48 of them female and 12 of them male) from the University of Kent participated in partial fulfillment of a course requirement. All were native English speakers, with normal or corrected-to-normal vision.

Materials and Apparatus. The face stimuli presented at encoding and test were grayscale head-and-shoulder photographs of 96 Caucasian men. The 48 faces from Experiment 1 were used in conjunction with 48 new faces taken from the Computer Vision Labora- 
tory, Faculty of Computer and Information Science, University of Ljubljana, Slovenia (www.lrv.fri.uni-lj.si/facedb.html). None of the faces had any distinctive marks (such as scars or birthmarks), wore glasses, or was bearded, and clothing cues were edited out. Since the photographs were collated from two different databases, they varied slightly in terms of background cues; therefore, all background cues were edited out of the stimuli presented in the recognition test. As in Experiment 1, two photographic views of each face were used; a full frontal view was presented consistently during the study phase, whereas a 3/4 view (facing left) was presented at test.

From the 96 faces, six sets of 12 faces were constructed on the basis that half of the faces in each set should belong to each of the two databases from which the stimuli had been collated. These were rotated as the first face in each face pair (i.e., faces in the study phase that were not targeted by the postexposure description task), the second face in each face pair (i.e., faces in the study phase that were targeted by the postexposure description task), and distractors (i.e., new faces in the recognition test) across the description and no-description conditions. In addition, two sets of 12 fillers were constructed to ensure equal numbers of old and new faces for the recognition test.

The stimuli were presented on a PC using SuperLab Pro for Windows. Each stimulus was created within a surface of $5.5 \times 6.5 \mathrm{~cm}$ and appeared in the center of the computer screen.

Design and Procedure. A $2 \times 2$ factorial design was employed, with description (description vs. no description) and face position in each pair (first face vs. second face) as within-participants factors. The dependent variables were discrimination $\left(d^{\prime}\right)$ and response bias $(C)$.

Each participant took part in a description and a no-description condition. Thus, the participants viewed two separate stimulus blocks during the experiment. Each block comprised a study phase, of 12 faces presented first paired with 12 faces presented second and a test phase with the same faces in $3 / 4$ views plus 12 new distractor faces and 12 filler faces (note that the 12 filler faces were not included in the analysis of the results). Note that in the description condition, the first face was always the nondescribed face, and the second face was always the described face. Six sets of 12 faces were rotated across conditions, so that every set appeared equally often as first face, second face, and distractors for an equal number of participants (i.e., for 10 participants within each condition) and no face was repeated for a particular participant. For the two additional sets of filler faces, one set was assigned to the description condition, and the other set to the no-description condition.

In addition, the order in which the participants undertook the description conditions was counterbalanced, with half of the 60 participants undertaking the description condition as the first experimental condition and half the no-description condition as the first experimental condition.

Each participant was tested individually. The following procedure was adopted for both the description and the no-description conditions. The participants were presented with 12 pairs of faces ( 24 faces in all). The faces in each pair were sequentially presented. Each face remained on the screen for $5 \mathrm{sec}$ and was preceded by a fixation cross presented for $150 \mathrm{msec}$. Following each pair of faces, there was a 15 -sec interval in which the participants undertook the experimental manipulation described below. At the end of the $15 \mathrm{sec}$, the computer sounded to alert the participants to return their attention to the screen. A prompt on the screen asked the participants to press the space bar on the keyboard in order to view the next pair of faces.

Prior to the study phase, the participants were informed that they should look at both faces, since they would later be asked to recognize the faces that they were about to see. The participants were also provided with instructions concerning the description task. In the description condition, the participants were asked to write a description of the second face in the pair only. The description instructions were as follows. "You will now be presented with several pairs of faces. Following each pair you are to write a description of the second face shown in the pair. Please be as complete in your descrip- tion as possible, so that another person seeing only your description could get as accurate an idea as possible of what the face is like." In the no-description condition, the participants engaged in a filler activity: Following each pair of faces, a number was presented on the computer screen, from which the participants had to count backward in intervals of 3, writing down the numbers on a blank sheet of paper as they counted back.

Note that the filler activity adopted here differs from the visual puzzle task presented in the no-description condition in Experiment 1 . The standard counting task is assumed to prevent verbal recoding and verbal rehearsal (e.g., Hagendorf, 1992, cited in Brandimonte \& Gerbino, 1996). In addition, since the present paradigm allows for the possibility of both facilitative and interfering effects of verbalization, we chose to more closely match the no description filler activity to that used in the interference paradigm in Brown and Lloyd-Jones $(2002,2003)$. Finally, if facilitative effects are observed here, it is clear they are not tied to a particular filler task in the control condition.

Immediately following the study phase, face recognition was tested in a yes/no recognition task in which the corresponding $3 / 4$ views of the 24 study faces were mixed randomly with $3 / 4$ views of 12 new faces and 12 fillers. The procedure and instructions for the recognition task were the same as those described in Experiment 1, and the second experimental condition followed immediately.

\section{Results}

Two-way ANOVAs were carried out on the discrimination data, with description (description vs. no description) and face position in each pair (first face vs. second face) as within-participants factors. Table 2 shows mean discrimination, response bias, hits, and false alarms as a function of description condition and face position. Note that in the design of the present experiment (and of Experiment 3), the same false alarm rate applies to faces presented first and second within the description and the no-description conditions. Therefore, measures of discrimination $\left(d^{\prime}\right)$ and response bias $(C)$ are related for face position. However, different false alarm rates apply to the description and the no-description conditions, and description is the main variable under consideration. We therefore will present analyses of response bias.

Discrimination. There was a significant main effect of description, significant by items only $\left[F_{1}(1,59)=2.61\right.$, $M S_{\mathrm{e}}=0.67$, n.s., and $F_{2}(1,71)=5.35, M S_{\mathrm{e}}=0.57, p<$ $.05]$. Faces were discriminated better in the description than in the no-description condition. There was also a significant main effect of face position, with discrimination better for faces presented second $\left[F_{1}(1,59)=58.23\right.$, $M S_{\mathrm{e}}=0.15, p<.001$, and $F_{2}(1,71)=50.53, M S_{\mathrm{e}}=$ $0.21, p<.001]$. This was qualified by a significant description $\times$ face position interaction $\left[F_{1}(1,59)=6.72\right.$, $M S_{\mathrm{e}}=0.17, p<.05$, and $F_{2}(1,71)=12.70, M S_{\mathrm{e}}=0.18$, $p<.01]$. Pairwise comparisons using $t$ tests revealed that for faces presented second, the ability to discriminate between old and new items was significantly better in the description than in the no-description condition $\left[t_{1}(59)=\right.$ $\left.2.53, p<.05 ; t_{2}(71)=4.01, p<.001\right]$. For faces presented first, however, there was no significant difference between the description and the no-description conditions $\left[t_{1}(59)=0.28\right.$, n.s.; $t_{2}(71)=0.24$, n.s. $]$.

Note that pairwise comparisons using $t$ tests also revealed that discrimination performance was better for 
Table 2

Means and Standard Deviations for Discrimination, Response Bias, Hits, and False Alarms for Experiment 2

\begin{tabular}{|c|c|c|c|c|c|c|c|c|}
\hline & \multicolumn{4}{|c|}{ Description } & \multicolumn{4}{|c|}{ No Description } \\
\hline & \multicolumn{2}{|c|}{ First Face } & \multicolumn{2}{|c|}{ Second Face } & \multicolumn{2}{|c|}{ First Face } & \multicolumn{2}{|c|}{ Second Face } \\
\hline & $M$ & $S D$ & $M$ & $S D$ & $M$ & $S D$ & $M$ & $S D$ \\
\hline$\overline{d^{\prime}}$ & 0.45 & 0.59 & 0.98 & 0.59 & 0.42 & 0.61 & 0.67 & 0.66 \\
\hline C & 0.40 & 0.40 & 0.14 & 0.34 & 0.32 & 0.42 & 0.20 & 0.43 \\
\hline \multirow[t]{2}{*}{ Hits } & 0.43 & 0.19 & 0.64 & 0.16 & 0.46 & 0.18 & 0.55 & 0.21 \\
\hline & & & $S D$ & & & & $S D$ & \\
\hline False alarms & & & 0.16 & & & & 0.17 & \\
\hline
\end{tabular}

Note-For the $d^{\prime}$ measure, larger values indicate a greater ability to discriminate between old and new items. For the $C$ measure, values above 0 indicate a conservative response bias, and values below 0 indicate a liberal response bias.

faces presented second than for those presented first, both in the description condition [a difference in $d^{\prime}$ of .53; $\left.t_{1}(59)=8.03, p<.001 ; t_{2}(71)=7.49, p<.001\right]$ and in the no-description condition [a difference in $d^{\prime}$ of .25 ; $\left.t_{1}(59)=3.01, p<.005 ; t_{2}(71)=2.82, p<.01\right]$. Thus, the interaction can also be accounted for by better discrimination performance for faces presented second, with this difference being greater for the description condition.

Response bias. There was a significant main effect of face position, with more liberal responding to faces presented second $\left[F_{1}(1,59)=58.21, M S_{\mathrm{e}}=0.04, p<.001\right.$, and $\left.F_{2}(1,71)=50.53, M S_{\mathrm{e}}=0.05, p<.001\right]$. In addition, there was a significant description $\times$ face position interaction $\left[F_{1}(1,59)=6.72, M S_{\mathrm{e}}=0.04, p<.05\right.$, and $\left.F_{2}(1,71)=12.70, M S_{\mathrm{e}}=0.04, p<.005\right]$. Pairwise comparisons using $t$ tests to examine the description versus no-description difference for each face position were not significant. However, there was more liberal responding to faces presented second than for those presented first for the description condition [a difference in $C$ of -.26 ; $\left.t_{1}(59)=-8.03, p<.001 ; t_{2}(71)=7.49, p<.001\right]$. Similarly, there was more liberal responding to faces presented second than for those presented first for the nodescription condition [a difference in $C$ of $-.12 ; t_{1}(59)=$ $\left.-3.00, p<.005 ; t_{2}(71)=-2.82, p<.01\right]$. Thus, the interaction can be accounted for by more liberal responding to faces presented second for both the description and the no-description conditions, with this difference being greater for the description condition. Note that the interaction is difficult to interpret, since face position response bias is related to discrimination (i.e., the same false alarm rate was used to measure both conditions). Nevertheless, the main finding was a lack of an overall effect of description on response bias. We therefore will not discuss this result further.

\section{Discussion}

As was predicted, verbal facilitation arose for those faces in the series that the participants had previously described, but not for those faces in the series that had not been described. These results are consistent with an account in which facilitation of face recognition is mediated by a memory representation corresponding to verbal activity.
However, it is also the case that recognition was better for the second face in each pair. This effect was evident for both the description and the no-description conditions and was larger for the description condition (a face position difference in $d^{\prime}$ of .53 for the description condition and .25 for the no-description condition). This is somewhat surprising, since the participants were informed that their ability to recognize all of the faces would be tested and, in the no-description control condition (unlike the description condition), the filler task was not associated with the face presented second in each pair.

We may have observed item-specific retroactive interference, whereby new learning impaired memory for preceding events (for reviews, see Chandler, 1991; Chandler, Gargano, \& Holt, 2001; Windschitl, 1996). Thus, presentation of the second face may have impaired memory for the first face in each pair. Two accounts of item-specific retroactive interference are predominant: (1) Memory for old information may be made less available when new information alters or otherwise affects the stored memory traces for old information (e.g., Loftus, 1975, 1981), or (2) the problem may be one of inaccessibility, where memories for old and new information coexist but interfere with each other at the time of retrieval (e.g., Bekerian \& Bowers, 1983; Chandler, 1991).

For instance, Chandler and Gargano (1998) have provided evidence that a discrimination process plays a central role in producing interference in picture recognition. According to this account, test cues activate the memory trace for the target and its competitors, and difficulty in discriminating between traces may cause interference effects. However, one also needs to explain, on this account, why interference is retroactive, rather than proactive - that is, why the face encountered second in each pair interfered with memory for the first face, but not vice versa. Chandler (1991) found a similar result. Using a blocked design with a series of nature scenes (i.e., the study pictures; for instance, of a beach) followed by related (experimental; another picture of the beach) or unrelated (control) conditions, Chandler found that recognition of study pictures was better in the control than in the experimental condition. However, no interference was found when the related pictures preceded the study pictures. Chandler 
suggested two theoretical possibilities, trace strength and retrieval blocking, both of which are applicable here. First, the strength of the memory trace may be greater for the second face, perhaps because within the trial event, the second face is more recent. Alternatively, there may be a blocking process, whereby the second face may steal activation from the first face or be sampled in its place (see also M. C. Anderson \& Bjork, 1994). These accounts also have the potential to explain why the position effect observed here was stronger when the second face was described than when it was not described. For instance, the verbal describing of the second face may have either increased the strength of the memory trace for the second face or may have led to activation of the second face at the expense of activation of the first face.

In sum, as was predicted, the pattern of our present results is consistent with an account emphasizing the effects of verbal facilitation on face recognition, whereby facilitation arose for those faces in the series that the participants had previously described, but not for those faces that had not been described. It is also possible, however, that some other process, such as discrimination or blocking, made retrieval problematic in this variant of the paradigm. Nevertheless, we will continue to focus on verbal facilitation. If it is the case that verbal facilitation is mediated by a memory representation corresponding to verbal activity, the nature of the verbal description may play a role in modulating the effects of verbalization on recognition memory. In Experiment 3, we instructed the participants to describe either differences or similarities between pairs of faces (or not, in the control condition) and examined whether verbal facilitation was influenced by the quality of the descriptions that were elicited.

\section{EXPERIMENT 3}

In Experiment 3, the participants were directed to consider both faces when providing their descriptions. We examined whether the nature of the information elicited by the description was important for performance. Distinctiveness is important for recollection (for reviews, see Hunt \& McDaniel, 1993; Schmidt, 1991). Furthermore, it is a robust finding that more distinctive faces are easier to recognize (e.g., Light, Kayra-Stuart, \& Hollander, 1979; Valentine \& Bruce, 1979). Indeed, this finding has been used as a constraint in the construction of a number of models of face memory (e.g., Valentine, 1991; Valentine \& Endo, 1992). We reasoned, therefore, that in general terms, instructions to describe differences between pairs of faces would encourage the description of distinctive aspects of each face, and this may be more beneficial for subsequent recognition than are instructions to describe similarities between faces, which encourage the description of less distinctive aspects of each face. A study by Mäntylä (1997) supports this suggestion. Mäntylä directed participants to focus upon either the differences or the similarities among faces by instructing them to either (1) rate the facial distinctiveness of each face or (2) sort faces into four student-type categories (intellectual, sporty, party-goer, and homebody). Although there was no effect of either task upon overall recognition performance, rating facial distinctiveness elicited more remember responses (i.e., responses that evoked some specific recollection from the study phase) at recognition than did the categorizing of faces.

In order to examine the nature of the descriptions in detail and provide converging evidence that the instructional manipulation was successful in encouraging the description of different aspects of each face, we carried out post hoc analyses of description quality. If verbal facilitation is mediated by a memory representation corresponding to verbal activity, we may expect an association between the quality of the participants' descriptions and recognition performance (i.e., recognition efficiency in the description condition and the amount of verbal facilitation that is observed). In studies of verbal facilitation, verbal descriptions have not been examined in this way. Nevertheless, Winograd $(1978,1981)$ and others have suggested that the number of features attended to and stored during encoding may be important. Wells and Hryciw (1984) suggested also that the encoding of more global impressions of the face may be beneficial for performance. In a similar vein, Brown and Lloyd-Jones (2002) have recently suggested that the proportion of featural and holistic descriptors elicited (i.e., descriptors of isolated facial features vs. descriptors consisting of judgments based on the whole face, such as personality, weight, and face shape) may be an important determinant of the effects of verbalization on face recognition. They found that description instructions that encouraged featural descriptors produced verbal interference on subsequent face recognition but that description instructions that encouraged recall of more holistic aspects of the face did not. Thus, we may predict a complementary effect here, so that instructions that encourage the recall of more holistic aspects of the face may be more beneficial for recognition performance than are instructions that encourage the recall of individual facial features.

In the present experiment, we compared instructions encouraging descriptions of either differences or similarities between pairs of faces. We also examined whether the proportion of featural and holistic descriptors, or the total amount of information that was generated by each description instruction, was associated with performance efficiency.

\section{Method}

Participants. There were 120 participants (100 of female and 20 of them male). All were University of Kent undergraduate students, participating in partial fulfillment of a course requirement. All were native English speakers or had spoken English since childhood.

Materials and Apparatus. The same materials and apparatus were used as those in Experiment 2.

Design and Procedure. A mixed $3 \times 2$ factorial design was employed. Description instruction (differences vs. similarities) was the between-participants factor. The two factors examined within each description instruction condition were description (description vs. no description) and face position in each pair (first face vs. second face). The dependent measures were discrimination $\left(d^{\prime}\right)$ and response bias $(C)$. The procedure was the same as that used in Experiment 2, except for a change to the description instructions. 
The participants were asked to describe differences or similarities between pairs of faces. The description instructions were as follows. "You will now be presented with several pairs of faces. Following each pair of faces you are to describe the way in which the two faces in the pair are DIFFERENT from (SIMILAR to) each other. Please be as complete in your description of the differences (similarities) between the faces as possible, so that another person seeing only your description could get as accurate an idea as possible of how the faces are different from (similar to) each other."

\section{Results}

The data were analyzed both in their complete form and with a trimming procedure in order to exclude cases in which the participant had not correctly carried out the description task. Two judges independently coded the 120 verbal descriptions (60 descriptions of differences and 60 of similarities) for descriptors referring to differences or similarities between the pairs of faces viewed at study. Across all 120 descriptions, the correlation between the two judges was $r=.99$ for both kinds of description. An estimate was obtained for each participant's description by averaging the two judges' ratings within each of the two coding categories. Stem and leaf displays were used to identify those descriptions containing an extreme number of descriptors not consistent with the description instruction the participants had been given. One difference description containing four descriptors of similarities and three similarities descriptions containing four or more descriptors of differences were excluded from the trimmed analysis. Thus, in the trimmed analysis, 1 participant was dropped from the differences condition, and 3 participants were dropped from the similarities condition. The results of the full and trimmed analyses were the same, and therefore we will report only the analysis of the trimmed data.

We first will report parametric analyses of recognition efficiency. A $3 \times 2$ ANOVA was carried out on discrimination $\left(d^{\prime}\right)$ and response bias $(C)$ measures, with description instruction (differences vs. similarities) as a between-participants factor and description (description vs. no description) and face position in each pair (first face vs. second face) as within-participants factors. Table 3 shows discrimination, response bias, hits, and false alarms as a function of description and face position for each description instruction (i.e., describing differences or similarities).

We also present post hoc analyses of description quality. We examined the proportion of featural and holistic descriptors, the total number of descriptors that were produced under the different instruction conditions, and how these variables were correlated with measures of recognition performance.

Discrimination. There was a significant main effect of description $\left[F_{1}(1,114)=6.10, M S_{\mathrm{e}}=0.45, p<.05\right.$, and $\left.F_{2}(1,71)=4.72, M S_{\mathrm{e}}=0.61, p<.05\right]$. Discrimination was significantly better in the description than in the nodescription condition. [Note that there was no description instruction $\times$ description interaction; $F_{1}(1,114)=0.32$, $M S_{\mathrm{e}}=0.45$, n.s., and $F_{2}(1,71)=0.12, M S_{\mathrm{e}}=.60$, n.s.]

Response bias. There was a main effect of description instruction, significant by items only $\left[F_{1}(1,114)=2.20\right.$, $M S_{\mathrm{e}}=0.25$, n.s., and $F_{2}(1,71)=7.31, M S_{\mathrm{e}}=0.11, p<$ $.01]$. There was more liberal responding following descriptions of similarities than following descriptions of differences, with mean response biases of .12 and .19, respectively. Note that there was no effect of description on response bias, and response bias will not be discussed further.

Description quality. To assess directly whether the description instruction manipulation influenced the quality of the participants' descriptions, two independent judges examined the proportion of featural and holistic descriptors (i.e., the total number of each type of descriptor divided by the total number of descriptors) and the mean total amount of information per pair of faces that was generated. Featural descriptors were taken from Brown and Lloyd-Jones (2002) and consisted of judgments about particular facial features: the size or shape of the chin, lips, nose, eyes, eyebrows, or

Table 3

Means and Standard Deviations for Discrimination, Response Bias, Hits, and

False Alarms for Experiment 3: Describing Differences and Similarities

\begin{tabular}{|c|c|c|c|c|c|c|c|c|}
\hline & \multicolumn{4}{|c|}{ Description } & \multicolumn{4}{|c|}{ No Description } \\
\hline & \multicolumn{2}{|c|}{ First Face } & \multicolumn{2}{|c|}{ Second Face } & \multicolumn{2}{|c|}{ First Face } & \multicolumn{2}{|c|}{ Second Face } \\
\hline & $M$ & $S D$ & $M$ & $S D$ & $M$ & $\overline{S D}$ & $M$ & $S D$ \\
\hline \multicolumn{9}{|c|}{ Differences } \\
\hline$d^{\prime}$ & 0.73 & 0.62 & 0.76 & 0.57 & 0.50 & 0.54 & 0.62 & 0.52 \\
\hline C & 0.17 & 0.32 & 0.16 & 0.32 & 0.23 & 0.38 & 0.17 & 0.42 \\
\hline \multirow[t]{2}{*}{ Hits } & 0.58 & 0.17 & 0.59 & 0.15 & 0.51 & 0.17 & 0.55 & 0.19 \\
\hline & & M & $S D$ & & & $M$ & $S D$ & \\
\hline False alarms & & 0.29 & 0.15 & & & 0.32 & 0.17 & \\
\hline \multicolumn{9}{|c|}{ Similarities } \\
\hline$d^{\prime}$ & 0.68 & 0.62 & 0.63 & 0.60 & 0.54 & 0.52 & 0.54 & 0.47 \\
\hline C & 0.12 & 0.27 & 0.14 & 0.31 & 0.09 & 0.27 & 0.10 & 0.28 \\
\hline \multirow[t]{2}{*}{ Hits } & 0.59 & 0.15 & 0.57 & 0.17 & 0.57 & 0.14 & 0.57 & 0.14 \\
\hline & & $M$ & $S D$ & & & $M$ & $S D$ & \\
\hline False alarms & & 0.33 & 0.15 & & & 0.35 & 0.15 & \\
\hline
\end{tabular}

Note-For the $d^{\prime}$ measure, larger values indicate a greater ability to discriminate between old and new items. For the $C$ measure, values above 0 indicate a conservative response bias, and values below 0 indicate a liberal response bias. 
forehead, the distance between two features (such as eyes close together), and hair length and texture. Holistic descriptors were classified according to categories derived from Coin and Tiberghien (1997) and consisted of judgments concerning personality (e.g., jolly, studious, intelligent, or pleasant), height, weight, age, global face structure (e.g., head shape, skin tone, expression, and comparative judgments about features such as chin was narrower than forehead), and hairstyle (see also O'Toole, Deffenbacher, Valentin, \& Abdi, 1994, who classify hairstyle as a holistic facial aspect). A small number of descriptors that did not fit into either of these two categories were classified as other descriptors. For the 116 participants' descriptions (59 descriptions of differences and 57 of similarities; see above) the correlations between the two independent judges were $r=.85$ for featural descriptors, $r=.84$ for holistic descriptors, and $r=.97$ for the mean number of descriptors. The average of the two judges' ratings was taken for each coding category, and the proportions of featural and holistic descriptors were calculated across the 12 pairs of faces. In addition, the mean number of descriptors generated for each of the 12 pairs of faces was also calculated.

Individual $t$ tests were used to examine whether descriptions of differences and similarities differed in terms of the three description quality measures, as follows.

1 . The describing of differences elicited a significantly greater proportion of holistic descriptors than did the describing of similarities $[t(114)=4.64, p<.001]$. The mean proportion of holistic descriptors was $.43(S D=$ $.15)$ for descriptions of differences and $.29(S D=.16)$ for descriptions of similarities.

2 . The describing of similarities elicited a significantly greater proportion of featural descriptors than did the describing of differences $[t(114)=-4.59, p<.001]$. The mean proportion of featural descriptors was $.70(S D=$ $.17)$ for descriptions of similarities and $.56(S D=.15)$ for descriptions of differences.

3 . The describing of differences elicited a significantly greater number of descriptors overall than did the describing of similarities $[t(114)=2.27, p<.05]$. The mean number of descriptors was $2.66(S D=0.59)$ for descriptions of differences and $2.38(S D=0.72)$ for descriptions of similarities.
In addition we examined whether there was a correlation between the participants' description quality (i.e., the proportion of featural and holistic details and the number of details generated) and (1) discrimination performance in the description condition and (2) the amount of verbal facilitation (calculated by subtracting $d^{\prime}$ scores in the no-description condition from $d^{\prime}$ scores in the description condition; higher scores indicated greater verbal facilitation). We also tested for significant differences between correlations. ${ }^{1}$ Tables 4 and 5 show the correlations between measures of description quality, discrimination, and verbal facilitation for descriptions of differences and similarities, respectively.

Table 4 shows that for descriptions of differences, the number of descriptors was positively correlated both with discrimination performance in the description condition $(p<.05)$ and with verbal facilitation $(p<.05)$. Thus, an increase in the number of descriptors generated was associated both with better recognition and with an increase in verbal facilitation. However, Table 5 shows that this was not the case for descriptions of similarities. A comparison of these correlations revealed that the correlation coefficients obtained when differences were described were not significantly different from those obtained when similarities were described (for description $d^{\prime}, z=1.78$, n.s.; for verbal facilitation, $z=1.92$, n.s.).

Table 5 also shows that for descriptions of similarities, the proportion of holistic descriptors was positively correlated with verbal facilitation $(p<.05)$. Thus, an increase in holistic descriptors was associated with an increase in verbal facilitation. However, Table 4 shows that this was not the case for descriptions of differences. A comparison of these correlations reveals a trend toward the correlation coefficient's being higher for descriptions of similarities than for descriptions of differences $(z=1.96, p=.05)$.

Finally, Table 5 shows that for descriptions of similarities, the proportion of featural descriptors was negatively correlated with verbal facilitation $(p<.05)$. Thus, an increase in featural descriptors was associated with a decrease in verbal facilitation. However, Table 4 shows that this was not the case for descriptions of differences. A comparison of these correlations revealed that the correlation coefficient was significantly higher for descriptions

Table 4

Correlations Between Description Quality and Discrimination and Verbal Facilitation Measures: Descriptions of Differences

\begin{tabular}{lccccc}
\hline \multicolumn{1}{c}{ Variables } & Featural & Holistic & Total & Description $d^{\prime}$ & Facilitation \\
\hline Featural & - & $-.99^{* *}$ & -.17 & -.13 & .03 \\
Holistic & & - & .19 & .14 & -.02 \\
Total & & & - & $.31^{*}$ & $.26^{*}$ \\
Description $d^{\prime}$ & & & & - & $.73^{* *}$ \\
Facilitation & & & & & - \\
\hline
\end{tabular}

Note-Featural, proportion of featural descriptors (featural/featural + holistic + other); holistic, proportion of holistic descriptors (holistic/featural + holistic + other); total, mean number of descriptors (holistic + featural + other; derived from each of the 12 pairs of faces); description $d^{\prime}, d^{\prime}$ scores in the description condition; facilitation, verbal facilitation, where larger values indicate greater verbal facilitation. ${ }^{*} p<.05 .{ }^{* *} p<.01$. 
Table 5

Correlations Between Description Quality and Discrimination and Verbal Facilitation Measures: Descriptions of Similarities

\begin{tabular}{lccccc}
\hline \multicolumn{1}{c}{ Variables } & Featural & Holistic & Total & Description $d^{\prime}$ & Facilitation \\
\hline Featural & - & $-.99^{* *}$ & -.15 & -.18 & $-.34^{*}$ \\
Holistic & & - & .16 & .18 & $.34^{* *}$ \\
Total & & & - & -.02 & -.10 \\
Description $d^{\prime}$ & & & & - & $.76^{* *}$ \\
Facilitation & & & & & - \\
\hline
\end{tabular}

Note-Featural, proportion of featural descriptors (featural/featural + holistic + other); holistic, proportion of holistic descriptors (holistic/featural + holistic + other); total, mean number of descriptors (holistic + featural + other; derived from each of the 12 pairs of faces); description $d^{\prime}, d^{\prime}$ scores in the description condition; facilitation, verbal facilitation, where larger values indicate greater verbal facilitation. ${ }^{*} p<.05 .{ }^{* *} p<.01$.

of similarities than for descriptions of differences $(z=$ $-2.01, p<.05)$.

\section{Discussion}

The describing of differences and the describing of similarities between pairs of faces facilitated their subsequent recognition in equal measure. This was the case even though careful analyses of description quality found descriptions of differences and similarities to differ in terms of both the quality and the amount of information elicited.

The correlation between measures of description quality and recognition suggested, however, that the nature of the descriptions may have contributed to the effects of verbal facilitation. In particular, for the describing of similarities, an increase in the generation of holistic information was associated with an increase in verbal facilitation. In contrast, an increase in the generation of featural information was associated with a decrease in verbal facilitation. We are aware, however, that although in line with the statistical power of similar analyses in the literature (e.g., Meissner, 2002; Meissner et al., 2001; Wells, 1985), these associations were not particularly strong. ${ }^{2}$ Nevertheless, this finding encouraged us to explore further the relationship between the generation of holistic information and verbal facilitation. In Experiment 4, we encouraged the participants to describe either more global or more featural impressions of each face and examined the influence of these descriptions on subsequent recognition.

Finally, note that we did not observe any effects of face position in this experiment (i.e., of the face presented first or second in each pair). Therefore, effects of verbal facilitation on face recognition in this variant of the paradigm cannot be explained in terms of verbalization's influencing item-specific retroactive interference-for instance, through a discrimination or blocking process that makes retrieval difficult.

\section{EXPERIMENT 4}

In Experiment 4, we examined the importance of holistic information for verbal facilitation of face recognition. We returned to the single-face description paradigm of
Experiment 1. We compared description instructions that encouraged the participants to generate holistic information about the face with description instructions that encouraged the participants to generate featural information about the face. We predicted that verbalization of holistic information would be more beneficial for subsequent recognition.

\section{Method}

Participants. Ninety-six undergraduate students ( 85 of them female and 11 of them male) from the University of Kent participated in partial fulfillment of a course requirement. All were native English speakers, with normal or corrected-to-normal vision.

Materials and Apparatus. The same materials and apparatus were used as those in Experiment 1. However, the stimuli were presented on a PC using SuperLab Pro for Windows. Each stimulus was created within a surface of $5.5 \times 6.5 \mathrm{~cm}$ and appeared in the center of the computer screen.

Design and Procedure. A mixed $2 \times 2$ factorial design was employed, with description instruction (holistic vs. featural) as a between-participants factor and description (description vs. no description) as the within-participants factor. The dependent measures were discrimination $\left(d^{\prime}\right)$ and response bias $(C)$.

The design and procedure was the same as those in Experiment 1, except for a change in the description instructions. The holistic description instructions were derived from categories used by Coin and Tiberghien (1997) and asked the participants to describe the person in terms of the following six characteristics: overall expression (e.g., stern, sad, or serious), overall head shape (e.g., round or rectangular), personality characteristics (e.g., snob, bully, or introverted), intelligence, attractiveness, and friendliness. The featural description instructions were derived from categories used by Brown and Lloyd-Jones (2002) and asked the participants to describe the person in terms of the shape, size, and appearance of the following six features: forehead, eyes and eyebrows, ears, nose, mouth, and chin.

\section{Results}

The descriptions were analyzed in the same way as in Experiment 3. Across all 96 descriptions, the correlation between the two judges was $r=.99$ for both holistic and featural descriptors. Five holistic descriptions containing 10 or more featural descriptors and 2 featural descriptions containing 10 or more holistic descriptors were excluded from the trimmed analysis. The results of the full and trimmed analyses were the same, and therefore we will report the analysis of the trimmed data. 
We first will report parametric analyses of recognition efficiency. Two-way mixed design ANOVAs were carried out on discrimination $\left(d^{\prime}\right)$ and response bias $(C)$ measures, with description instruction (holistic vs. featural) as a between-participants factor and description (description vs. no description) as the within-participants factor. Table 6 shows discrimination, response bias, hits, and false alarms as a function of description condition for each description instruction.

We also will present post hoc analyses of description quality. We examined the proportion of holistic and featural descriptors, the total number of descriptors that were produced under the different instruction conditions, and how these variables were correlated with measures of recognition performance.

Discrimination. There was a main effect of description, with better discrimination in the description than in the nodescription condition $\left[F_{1}(1,87)=8.56, M S_{\mathrm{e}}=0.39, p<\right.$ .005 , and $\left.F_{2}(1,47)=6.94, M S_{\mathrm{e}}=0.37, p<.05\right]$. There was also a main effect of description instruction, with better discrimination in the featural than in the holistic description instruction condition, significant by items only $\left[F_{1}(1,87)=\right.$ $1.52, M S_{\mathrm{e}}=0.42$, n.s., and $F_{2}(1,47)=6.95, M S_{\mathrm{e}}=0.74$, $p<.05$ ]. [Note that there was no description instruction $\times$ description interaction; $F_{1}(1,87)=0.07, M S_{\mathrm{e}}=0.39$, n.s., and $F_{2}(1,47)=0.01, M S_{\mathrm{e}}=0.40$, n.s.]

Response bias. There was a main effect of description, with more liberal responding in the description than in the no-description condition $\left[F_{1}(1,87)=6.41, M S_{\mathrm{e}}=\right.$ $0.05, p<.05$, and $F_{2}(1,47)=7.00, M S_{\mathrm{e}}=0.13, p<$ $.05]$. There was also a main effect of description instruction, with more liberal responding in the holistic than in the featural description instruction condition, significant by items only $\left[F_{1}(1,87)=0.41, M S_{\mathrm{e}}=0.12\right.$, n.s., and $\left.F_{2}(1,47)=8.35, M S_{\mathrm{e}}=0.18, p<.01\right]$. [Note that there was no description instruction $\times$ description interaction; $F_{1}(1,87)=2.31, M S_{\mathrm{e}}=0.05$, n.s., and $F_{2}(1,47)=0.26$, $\left.M S_{\mathrm{e}}=0.07, \mathrm{n.s}.\right]$

Table 6

Means and Standard Deviations for Discrimination, Response Bias, Hits, and False Alarms for Experiment 4: Holistic and Featural Description Instructions

\begin{tabular}{|c|c|c|c|c|}
\hline & \multicolumn{2}{|c|}{ Description } & \multicolumn{2}{|c|}{ No Description } \\
\hline & $M$ & $S D$ & $M$ & $S D$ \\
\hline \multicolumn{5}{|c|}{ Holistic } \\
\hline$d^{\prime}$ & 1.02 & 0.54 & 0.73 & 0.71 \\
\hline C & 0.26 & 0.28 & 0.30 & 0.36 \\
\hline Hits & 0.60 & 0.14 & 0.52 & 0.19 \\
\hline False alarms & 0.22 & 0.12 & 0.26 & 0.16 \\
\hline \multicolumn{5}{|c|}{ Featural } \\
\hline$d^{\prime}$ & 0.88 & 0.59 & 0.63 & 0.68 \\
\hline C & 0.18 & 0.25 & 0.31 & 0.26 \\
\hline Hits & 0.60 & 0.13 & 0.50 & 0.16 \\
\hline False alarms & 0.26 & 0.15 & 0.27 & 0.15 \\
\hline
\end{tabular}

Note-For the $d^{\prime}$ measure, larger values indicate a greater ability to discriminate between old and new items. For the $C$ measure, values above 0 indicate a conservative response bias, and values below 0 indicate a liberal response bias.
Description quality. To assess whether the description instruction manipulation influenced the quality of the participants' descriptions, the descriptions were examined for the proportion of holistic and featural descriptors that they contained, as well as the mean total amount of information generated (see the description quality section of Experiment 3 for full details of the coding procedure). Individual $t$ tests were used to examine whether holistic and featural instructions generated descriptions that differed in terms of the three description quality measures, as follows.

1. Holistic instructions elicited a significantly greater proportion of holistic descriptors than did featural instructions $[t(87)=49.03, p<.001]$. The mean proportion of holistic descriptors was .94 $(S D=.09)$ for holistic instructions and $.08(S D=.08)$ for featural instructions.

2. Featural instructions elicited a significantly greater proportion of featural descriptors than did holistic instructions $[t(87)=-49.03, p<.001]$. The mean proportion of featural descriptors was $.92(S D=.08)$ for featural instructions and $.06(S D=.09)$ for holistic instructions.

3. Holistic instructions elicited a significantly greater number of descriptors overall than did featural instructions $[t(87)=3.12, p<.01]$. The mean number of details per face pair was $3.48(S D=0.50)$ for holistic instructions and $3.13(S D=0.55)$ for featural instructions.

We also examined whether there was a correlation between the participants' description quality and recognition performance. Tables 7 and 8 show the correlations between measures of description quality, discrimination, and verbal facilitation for holistic and featural descriptions, respectively.

Table 7 shows that for holistic descriptions, the number of descriptors was negatively correlated with verbal facilitation $(p<.05)$. Thus, an increase in the number of descriptors generated was associated with a reduction in the facilitative effect of verbalization. In contrast, Table 8 shows that for featural descriptions, the number of descriptors was positively correlated with verbal facilitation $(p<.05)$. Thus, an increase in the number of descriptors generated was associated with an increase in the facilitative effect of verbalization. A comparison of these correlation coefficients shows them to be significantly different $(z=-3.03, p<.01)$.

Table 8 also shows that for featural descriptions, the number of descriptors was positively correlated with discrimination performance $(p<.05)$. However, Table 7 shows that this was not the case for holistic descriptions. A comparison of these correlation coefficients shows them to be significantly different $(z=2.10, p<.05)$.

\section{Discussion}

Describing both holistic and featural aspects of a face facilitated subsequent face recognition. Verbal facilitation was of a similar magnitude across both description instructions. This was the case despite the fact that careful analyses of description quality showed that holistic and featural descriptions differed in terms of the amount and quality of information they contained.

The pattern of correlation between description quality and recognition performance was interesting. The gener- 
Table 7

Correlations Between Description Quality and Discrimination and Verbal Facilitation Measures: Holistic Descriptions

\begin{tabular}{lccccc}
\hline \multicolumn{1}{c}{ Variables } & Featural & Holistic & Total & Description $d^{\prime}$ & Facilitation \\
\hline Featural & - & $-1.00^{* *}$ & -.23 & .14 & .13 \\
Holistic & & - & .23 & -.14 & -.13 \\
Total & & & - & -.06 & $-.34^{*}$ \\
Description $d^{\prime}$ & & & & - & $.38^{*}$ \\
Facilitation & & & & & - \\
\hline
\end{tabular}

Note-Featural, proportion of featural descriptors (featural/featural + holistic + other); holistic, proportion of holistic descriptors (holistic/featural + holistic + other); total, mean number of descriptors (holistic + featural + other; derived from each of the 12 pairs of faces); description $d^{\prime}, d^{\prime}$ scores in the description condition; facilitation, verbal facilitation, where larger values indicate greater verbal facilitation. ${ }^{*} p<.05 .{ }^{* *} p<.01$.

ating of more descriptors was correlated with increasing verbal facilitation when featural aspects of the face were described but with decreasing verbal facilitation when more holistic aspects of the face were described. There may have been a trade-off between the usefulness of holistic information in making faces distinctive and, hence, benefiting retrieval and additional information's increasing the similarity between targets and competitors, which interfered with retrieval. Nevertheless, we must note that, as with Experiment 3, the power of these correlations was not particularly strong (ranging from -.34 to +.38 ) and that they must, therefore, be interpreted with caution.

Finally, verbalization influenced response bias in the same way as in Experiment 1. More liberal responding arose when the participants had previously provided descriptions of faces. However, the false alarm rate was similar across both the description and the no-description conditions (.24 and .26, respectively), which suggests that differences in response bias were driven predominantly by responses to old faces, rather than by errors to new faces.

\section{GENERAL DISCUSSION}

Using a novel paradigm, we have established that the verbal describing of a visual memory of a face can benefit subsequent visual recognition of that same face. Verbalizing a memory of a single face (in Experiments 1 and 4) or the relationship between pairs of previously presented faces (in Experiment 3) was found to benefit recognition. There was also evidence that facilitative effects of verbalization may be tied to the stimulus that is described (in Experiment 2). However, an alternative account of this particular finding is also possible - namely, that verbalization influenced item-specific retroactive interference (whereby new learning impairs memory for preceding events; for reviews, see Chandler, 1991; Windschitl, 1996). Finally, the nature of the description did not appear to be a strong determinant of verbal facilitation, although we noted some evidence for an association between description quality and recognition performance. The describing of differences and similarities between pairs of faces gave rise to similar amounts of facilitation (Experiment 3). Similarly, the describing of more holistic aspects (such as global face structure and perceived personality) and the describing of more local features (such as size or shape of the chin, nose, or eyes) of a single face also gave rise to similar amounts of facilitation (Experiment 4).

One concern with the present findings is that they may not reflect a facilitative effect of verbally describing each face but, rather, a detrimental effect of engaging in a distractor activity following presentation of each face in the no-description control condition. We know that distractor tasks can influence recognition performance. For instance, the revelation effect is the tendency to call an item on a recognition test old if it is preceded by a different task interpolated between study and test (e.g.,

Table 8

Correlations Between Description Quality and Discrimination and Verbal Facilitation Measures: Featural Descriptions

\begin{tabular}{lccccc}
\hline \multicolumn{1}{c}{ Variables } & Featural & Holistic & Total & Description $d^{\prime}$ & Facilitation \\
\hline Featural & - & $-1.00^{* * *}$ & .09 & -.08 & -.12 \\
Holistic & & - & -.09 & .08 & .12 \\
Total & & & - & $.38^{*}$ & $.30^{*}$ \\
Description $d^{\prime}$ & & & & - & $.77^{* * *}$
\end{tabular}

Facilitation

Note-Featural, proportion of featural descriptors (featural/featural + holistic + other); holistic, proportion of holistic descriptors (holistic/featural + holistic + other); total, mean number of descriptors (holistic + featural + other; derived from each of the 12 pairs of faces); description $d^{\prime}, d^{\prime}$ scores in the description condition; facilitation, verbal facilitation, where larger values indicate greater verbal facilitation. ${ }^{*} p<.05 .{ }^{* * *} p<.001$. 
Hicks \& Marsh, 1998; Watkins \& Peynircioğlu, 1990; Westerman \& Greene, 1998). We cannot altogether discard this notion. However, there are a number of reasons why we consider it unlikely. First, the distractor tasks used here-namely, solving visual puzzles and counting backward - were very different from the task of learning faces. Thus, we would expect that the participants would be able to differentiate easily between the two tasks and to prevent one from contaminating the other (cf. Westerman \& Greene, 1998, p. 385). Second, a number of authors have suggested that an interpolated distractor task produces a liberal shift in participants' response criterion, and therefore we might expect an effect of the distractor task to be accompanied by more liberal responding in the recognition test (e.g., Bornstein \& Wilson, 2004; Hicks \& Marsh, 1998; Niewiadomski \& Hockley, 2001; although see Westerman \& Greene, 1996, 1998). In fact, the participants adopted a more conservative response criterion in the no-description condition (i.e., where they undertook the distractor task) than in the description condition. Finally, if the present findings were due solely to a negative influence of distractor activity on performance, we would not expect a relationship between the quality of the participants' descriptions and their subsequent recognition memory. However, there was some evidence for such a relationship. We argue, therefore, that the effects of discrimination observed in the present paradigm are more likely to have been the result of facilitative effects of verbalization than a negative effect of the distractor activity in the control condition.

\section{Sources of Facilitation}

There are several possibilities as to why verbalization benefited face recognition in this paradigm. First, facilitation may be due to a greater number of features attended to, and stored, during encoding (e.g., Winograd, 1978, 1981). Second, facilitation may be due to the visual encoding of more holistic aspects of the face, which we suggest is conjoint information regarding individual features (such as the eyes, nose, and mouth) and the spatial relations between them (see, e.g., Wells \& Hryciw, 1984; see also Peterson \& Rhodes, 2003). Third, facilitation may be due to the formation of richer semantic associations with the described face, which benefits retrieval (e.g., J. R. Anderson \& Reder, 1979; Bruce \& Young, 1986; Ryan \& Schooler, 1994, cited in Schooler et al., 1996). Finally, facilitation may have been due to semantic processing's influencing visual encoding strategies. Klatzky et al. (1982) found that faces presented in congruent semantic contexts (i.e., a face previously rated as stereotypical of a particular occupational category was presented with a written statement concerning the same occupation) were recognized better than faces in incongruent contexts. Interestingly, the participants made more false alarms at test to new faces that had previously been rated as stereotypical of a particular category than to faces that had not been rated as stereotypical. Klatzky et al. suggested that faces are associated with a particular category and this semantic information can bias responses to new faces that are similar to the category stereotype. In this way, semantic information influences the visual encoding of faces that have not been encountered previously. In the present experiments, there was evidence that verbalization influenced response bias. The participants were more liberal in their responding when they had previously provided a description. However, a closer look at the data showed that in both cases, the false alarm rate was similar across conditions, and so the benefit of verbalization was primarily on responding to previously encountered faces.

The present paradigm differs from previous paradigms used to investigate verbal facilitation effects on face recognition in that the participants described their visual memory of a face (or pair of faces), rather than making a judgment or describing a face while it was presented (although see Bartlett, Hurry, \& Thorley, 1984). This means that processes other than those described above may have come into play. One possibility is that verbalization provided an action tag to the stored visual memory of an unfamiliar face, which helped to differentiate it from other faces that had been presented. We can think of an action tag as additional information that is attached to the visual memory representation and specifies visual or semantic aspects of the face that are useful (or diagnostic) for successful recognition. When the face is re-presented, the action tag specifies, or directs processing toward, information relevant to the task (cf. DeSchepper \& Triesman, 1996; Neill \& Valdes, 1992; Ryan \& Schooler, 1994, cited in Schooler et al., 1996).

\section{Facilitation Versus Interference}

The facilitative effects of verbalization observed here contrast with the effects of verbal interference that have been documented elsewhere (e.g., Brown \& Lloyd-Jones, 2002, 2003; Meissner et al., 2001; Schooler \& EngstlerSchooler, 1990). In particular, Brown and Lloyd-Jones $(2002,2003)$ found verbal interference in a recognition paradigm in which participants described a single face following the study of a series of faces. They argued that verbal interference is mediated by a generalized shift in processing style from more holistic visual processing to the processing of individual facial features, which are less useful for subsequent recognition. In contrast, in the present paradigm, verbal facilitation arose when the participants described each studied face. It may be the case, therefore, that the facilitative effects of verbalization are tied to the face that is described. The present experiments did not provide conclusive evidence on this. Nevertheless, previous accounts of verbal facilitation have emphasized the importance of elaborations to memory representations corresponding to a particular face.

A further difference between the present paradigm and those in which verbal interference was observed is that the amount of time given to describing the face was relatively short (i.e., $15 \mathrm{sec}$ ), in comparison with paradigms that elicit verbal overshadowing (i.e., typically $5 \mathrm{~min}$; Brown \& Lloyd-Jones, 2002, 2003; Meissner et al., 2001; Schooler \& Engstler-Schooler, 1990). The amount of verbalization has been found to be a critical variable in deter- 
mining the reliability of the verbal overshadowing effect (e.g., Meissner \& Brigham, 2001) and may also be important for observing contrasting facilitative and interfering effects of verbalization on face memory.

Finally, the present research has implications for an applied forensic setting. Witnesses may see many faces at the time of the witnessed event that they are later called upon to describe. Police officers may also require descriptions of other witnesses who were present and who need to be traced. Moreover, witnesses may be exposed to multiple mugshots after the event (i.e., photographs fitting the witnesses description or photographs of suspects who have previously committed similar crimes in the area) that may be described, either overtly or covertly. In light of these circumstances, it is important to consider the potential impact of providing descriptions of several individuals seen within a similar encoding context. Despite the fact that descriptions of faces are often vague and imprecise (Ellis et al., 1980; Lindsay, Martin, \& Webber, 1994) and that some authors have suggested that providing descriptions may interfere with subsequent identification (e.g., Brown \& Lloyd-Jones, 2003), the present experiments show that providing descriptions of multiple faces can benefit their subsequent recognition. Furthermore, constraining witnesses to describe faces in a particular way-for instance, by focusing on holistic aspects of the face-may increase this benefit.

The paradigm developed here, which allows for both free descriptions and descriptions in which participants are constrained to describe either single faces or comparisons between pairs of faces in a particular way and which allows the association of qualitative and quantitative aspects of face descriptors with recognition performance, should provide further insight into the nature of the effects of verbalization on face recognition and the benefits of verbal descriptions of face memories in applied settings.

\section{REFERENCES}

Anderson, J. R., \& Reder, L. M. (1979). An elaborative processing explanation of depth of processing. In L. S. Cermak \& F. I. M. Craik (Eds.), Levels of processing in human memory (pp. 385-403). Hillsdale, NJ: Erlbaum.

Anderson, M. C., \& BJoRK, R. A. (1994). Mechanisms of inhibition in long-term memory: A new taxonomy. In D. Dagenbach \& T. H. Carr (Eds.), Inhibitory processes in attention, memory, and language (pp. 265-325). San Diego: Academic Press.

BADDEley, A. D., \& WoODHEAD, M. (1983). Improving face recognition ability. In S. M. A. Lloyd-Bostock \& B. R. Clifford (Eds.), Evaluating witness evidence (pp. 125-136). Chichester, U.K.: Wiley.

Bartlett, J. C., Hurry, S., \& Thorley, W. (1984). Typicality and familiarity of faces. Memory \& Cognition, 12, 219-228.

Bekerian, D. A., \& Bowers, J. M. (1983). Eyewitness testimony: Were we misled? Journal of Experimental Psychology: Learning, Memory, \& Cognition, 9, 139-145.

Berman, G. L., \& Cutler, B. L. (1998). The influence of processing instructions at encoding and retrieval on face recognition accuracy. Psychology, Crime \& Law, 4, 89-106.

Blaney, R. L., \& WinogRad, E. (1978). Developmental differences in children's recognition memory for faces. Developmental Psychology, 14, 441-442.

BLoom, L., \& MudD, S. A. (1991). Depth of processing approach to face recognition: A test of two theories. Journal of Experimental Psychology: Learning, Memory, \& Cognition, 17, 556-565.
Bornstein, B. H., \& WiLson, J. R. (2004). Extending the revelation effect to faces: Haven't we met before? Memory, 12, 140-146.

Bower, G. H., \& KarLin, M. B. (1974). Depth of processing pictures of faces and recognition memory. Journal of Experimental Psychology, 103, 751-757.

Brandimonte, M. A., \& Gerbino, W. (1996). When imagery fails: Effects of verbal recoding on accessibility of visual memories. In C. Cornoldi, R. H. Logie, M. A. Brandimonte, G. Kaufmann, \& D. Reisberg (Eds.), Stretching the imagination: Representation and transformation in mental imagery (pp. 31-76). New York: Oxford University Press.

BRown, C., \& Lloyd-Jones, T. J. (2002). Verbal overshadowing in a multiple face presentation paradigm: Effects of description instruction. Applied Cognitive Psychology, 16, 873-885.

Brown, C., \& LLOYD-Jones, T. J. (2003). Verbal overshadowing of multiple face and car recognition: Effects of within- versus acrosscategory verbal descriptions. Applied Cognitive Psychology, 17, 183201.

Bruce, V., \& Young, A. W. (1986). Understanding face recognition. British Journal of Psychology, 77, 305-327.

Chandler, C. C. (1991). How memory for an event is influenced by related events: Interference in modified recognition tests. Journal of Experimental Psychology: Learning, Memory, \& Cognition, 1, 115-125.

Chandler, C. C., \& Gargano, G. J. (1998). Retrieval processes that produce interference in modified forced-choice recognition tests. Memory \& Cognition, 26, 220-231.

Chandler, C. C., Gargano, G. J., \& Holt, B. C. (2001). Witnessing postevents does not change memory traces, but can affect their retrieval. Applied Cognitive Psychology, 15, 3-22.

Coin, C., \& Tiberghien, G. (1997). Encoding activity and face recognition. Memory, 5, 545-568.

Courtois, M. R., \& Mueller, J. H. (1979). Processing multiple physical features in facial recognition. Bulletin of the Psychonomic Society, 14, 74-76.

Davies, G., ShePherd, J., \& Ellis, H. (1979). Effects of interpolated mugshot exposure on accuracy of eyewitness identification. Journal of Applied Psychology, 64, 232-237.

Deffenbacher, K. A., CarR, T. H., \& Leu, J. R. (1981). Memory for words, pictures, and faces: Retroactive interference, forgetting, and reminiscence. Journal of Experimental Psychology: Human Learning \& Memory, 7, 299-305.

DeSchepper, B., \& Triesman, A. (1996). Visual memory for novel shapes: Implicit coding without attention. Journal of Experimental Psychology: Learning, Memory, \& Cognition, 22, 27-47.

Dodson, C. S., Johnson, M. K., \& Schooler, J. W. (1997). The verbal overshadowing effect: Why descriptions impair face recognition. Memory \& Cognition, 25, 129-139.

Ellis, H. D., Shepherd, J. W., \& Davies, G. M. (1980). The deterioration of verbal descriptions of faces over different delay intervals. Journal of Police Science \& Administration, 8, 101-106.

GLuCKSBERG, S. (1988). Language and thought. In R. J. Sternberg \& E. E. Smith (Eds.), The psychology of human thought (pp. 214-241). Cambridge: Cambridge University Press.

HARLEY, T. A. (1995). The psychology of language: From data to theory. Hove, U.K.: Taylor \& Francis.

HiCKS, J. L., \& MARSH, R. L. (1998). A decrement-to-familiarity interpretation of the revelation effect from forced-choice tests of recognition memory. Journal of Experimental Psychology: Learning, Memory, \& Cognition, 24, 1105-1120.

Howell, D. C. (1997). Statistical methods for psychology (4th ed.). Belmont, CA: Duxbury.

Hunt, R. R., \& MCDaniel, M. A. (1993). The enigma of organization and distinctiveness. Journal of Memory \& Language, 32, 421-445.

KerR, N. H., \& WinOGRAD, E. (1982). Effects of contextual elaboration on face recognition. Memory \& Cognition, 10, 603-609.

Klatzky, R. L., Martin, G. L., \& Kane, R. A. (1982). Semantic interpretation effects on memory for faces. Memory \& Cognition, 10, 195-206.

Light, L. L., Kayra-Stuart, F., \& Hollander, S. (1979). Recognition memory for typical and unusual faces. Journal of Experimental Psychology: Human Learning \& Memory, 5, 212-228.

Lindsay, R. C. L., Martin, R., \& Webber, L. (1994). Default values 
in eyewitness descriptions: A problem for the match-to-description lineup foil selection strategy. Law \& Human Behavior, 18, 527-541.

LofTus, E. F. (1975). Leading questions and eyewitness report. Cognitive Psychology, 7, 560-572.

LofTUs, E. F. (1981). Mentalmorphosis: Alteration in memory produced by the mental bonding of new information to old. In J. [B.] Long \& A. [D.] Baddeley (Eds.), Attention and performance IX (pp. 417-434). Hillsdale, NJ: Erlbaum.

MÄNTylä, T. (1997). Recollections of faces: Remembering differences and knowing similarities. Journal of Experimental Psychology: Learning, Memory, \& Cognition, 23, 1203-1216.

McKelvie, S. J. (1985). Effect of depth of processing in recognition memory for normal and inverted photographs of faces. Perceptual \& Motor Skills, 60, 503-508.

McKelvie, S. J. (1991). Effects of processing strategy and transformations on recognition memory for photographs of faces. Bulletin of the Psychonomic Society, 29, 98-100.

McKelvie, S. J. (1995). Encoding operations and recognition memory for faces. Canadian Journal of Experimental Psychology, 49, 437-458.

MCKelviE, S. J. (1996). Effects of encoding operations on recognition memory for upright and inverted faces. Australian Journal of Psychology, 48, 75-85.

Meissner, C. A. (2002). Applied aspects of the instructional bias effect in verbal overshadowing. Applied Cognitive Psychology, 16, 911-928.

Meissner, C. A., \& Brigham, J. C. (2001). A meta-analysis of the verbal overshadowing effect in face identification. Applied Cognitive Psychology, 15, 603-616.

Meissner, C. A., Brigham, J. C., \& Kelley, C. M. (2001). The influence of retrieval processes in verbal overshadowing. Memory \& Cognition, 29, 176-186.

Mueller, J. H., Courtois, M. R., \& Bailis, K. L. (1981). Self-reference in facial recognition. Bulletin of the Psychonomic Society, 17, 85-88.

Mueller, J. H., \& Wherry, K. L. (1980). Orienting strategies at study and test in facial recognition. American Journal of Psychology, 93, 107-117.

NeIll, W. T., \& VAldes, L. A. (1992). Persistence of negative priming: Steady state or decay? Journal of Experimental Psychology: Learning, Memory, \& Cognition, 18, 565-576.

NieWIAdOMSKI, M. W., \& HockLEY, W. E. (2001). Interrupting recognition memory: Tests of familiarity-based accounts of the revelation effect. Memory \& Cognition, 29, 1130-1138.

O’Toole, A. J., Deffenbacher, K. A., Valentin, D., \& Abdi, H. (1994). Structural aspects of face recognition and the other-race effect. Memory \& Cognition, 22, 208-224.

Patterson, K. E., \& Baddeley, A. D. (1977). When face recognition fails. Journal of Experimental Psychology: Human Learning \& Memory, 3, 406-417.

Peterson, M. A., \& Rhodes, G. (2003). The perception of faces, objects, and scenes: Analytic and holistic processes. London: Oxford University Press.

SchmidT, S. R. (1991). Can we have a distinctive theory of memory? Memory \& Cognition, 19, 523-542.

Schooler, J. W. (2002). Verbalization produces a transfer inappropriate processing shift. Applied Cognitive Psychology, 16, 989-997.

Schooler, J. W., \& Engstler-Schooler, T. Y. (1990). Verbal overshadowing of visual memories: Some things are better left unsaid. Cognitive Psychology, 22, 36-71.

Schooler, J. W., Fiore, S. M., \& Brandimonte, M. A. (1997). At a loss from words: Verbal overshadowing of perceptual memories. In D. L. Medin (Ed.), The psychology of learning and motivation: Advances in research and theory (Vol. 37, pp. 291-340). London: Academic Press.

Schooler, J. W., Ryan, R. S., \& Reder, L. (1996). The costs and benefits of verbally rehearsing memory for faces. In D. Hermann, M. Johnson, C. McEvoy, C. Hertzog, \& P. Hertel (Eds.), Basic and applied memory: New findings (pp. 51-65). Mahwah, NJ: Erlbaum.

SnOdgrass, J. G., \& CorwIN, J. (1988). Pragmatics of measuring recognition memory: Applications to dementia and amnesia. Journal of Experimental Psychology: General, 117, 34-50.

SPORER, S. L. (1991). Deep - deeper-deepest? Encoding strategies and the recognition of human faces. Journal of Experimental Psychology: Learning, Memory, \& Cognition, 17, 323-333.

Valentine, T. (1991). A unified account of the effects of distinctiveness, inversion, and race in face recognition. Quarterly Journal of Experimental Psychology, 43A, 161-204.

VAlentine, T., \& Bruce, V. (1979). The effects of distinctiveness in recognizing faces. Perception, 15, 525-536.

VAlentine, T., \& ENDO, M. (1992). Towards an exemplar model of face processing: The effects of race and distinctiveness. Quarterly Journal of Experimental Psychology, 44A, 671-703.

Watkins, M. J., \& PeynircioǦLu, Z. F. (1990). The revelation effect: When distinguishing test items induces recognition. Journal of Experimental Psychology: Learning, Memory, \& Cognition, 16, 1012-1020.

Wells, G. L. (1985). Verbal descriptions of faces from memory: Are they diagnostic of identification accuracy? Journal of Applied Psychology, 70, 619-626.

Wells, G. L., \& Hryciw, B. (1984). Memory for faces: Encoding and retrieval operations. Memory \& Cognition, 12, 338-344.

Westerman, D. L., \& Greene, R. L. (1996). On the generality of the revelation effect. Journal of Experimental Psychology: Learning, Memory, \& Cognition, 22, 1147-1153.

Westerman, D. L., \& Greene, R. L. (1998). The revelation that the revelation effect is not due to revelation. Journal of Experimental Psychology: Learning, Memory, \& Cognition, 24, 377-386.

Westerman, D. L., \& LARSEN, J. D. (1997). Verbal-overshadowing effect: Evidence for a general shift in processing. American Journal of Psychology, 110, 417-428.

Windschith, P. D. (1996). Memory for faces: Evidence of retrievalbased impairment. Journal of Experimental Psychology: Learning, Memory, \& Cognition, 22, 1101-1122.

WinOGRAD, E. (1976). Recognition memory for faces following nine different judgments. Bulletin of the Psychonomic Society, 8, 419-421.

WINOGRAD, E. (1978). Encoding operations which facilitate memory for faces across the life span. In M. M. Gruneberg, P. E. Morris, \& R. N. Sykes (Eds.), Practical aspects of memory (pp. 252-262). San Diego: Academic Press.

Winograd, E. (1981). Elaboration and distinctiveness in memory for faces. Journal of Experimental Psychology: Human Learning \& Memory, 7, 181-190.

\section{NOTES}

1. We tested the difference between two independent $r$ s in the following way: We transformed $r$ (correlation coefficient) to Fisher's $r^{\prime}$ (using a transformation table; see Howell, 1997, p. 682) and then used the formula $\left(r_{1}^{\prime}-r_{2}^{\prime}\right) /\left[1 /\left(N_{1}-3\right)+1 /\left(N_{2}-3\right)\right]^{1 / 2}$ to calculate a value of $z$ (see Howell, 1997, pp. 261-262). The value of $z$ is required to exceed \pm 1.96 to be significant at an alpha level of .05 (two-tailed).

2. In light of the findings concerning description quality in Experiment 3, we went back and examined description quality in Experiments 1 and 2 . There were no significant correlations between measures of description quality and recognition.

(Manuscript received August 18, 2004; revision accepted for publication December 16, 2004.) 